\section{MOLECULAR BIOLOGY}

Building DNA

\section{from our Molecular Biology Correspondent}

THE hoary problem of the mechanism of DNA replication has appeared in a new light since the discovery last year of the polynucleotide ligase enzyme. It had been noted previously, in experiments on two strains of $E$. coli, that freshly synthesized DNA appears in the form of small (about $7 S$ ) single-stranded segments which are only later incorporated into double-stranded DNA of high molecular weight. Okazaki et al., who reported these experiments, suggested that the ligase must be at work in this latter part of the replication process, a suggestion which has now been confirmed independently and by identical means in two laboratories.

Newman and Hanawalt (J. Mol. Biol., 35, 639; 1968 ) and Sugimoto, Okazaki and Okazaki (Proc. US Nat, Acad. Sci., 60, 1356; 1968) have both availed themselves of a mutant of T4 bacteriophage, which directs the synthesis of a ligase, functional at $25^{\circ} \mathrm{C}$, but inactivated at $37^{\circ} \mathrm{C}$. Pulse-labelling experiments with thymidine show a high concentration of the low molecular weight fragments in infected cells grown at $43^{\circ} \mathrm{C}$. In due course some high molecular weight material is formed, and some small amount of ligase activity, from phage or host, is therefore present. The difference, however, between these and cells infected by the mutant phage but grown at $23^{\circ} \mathrm{C}$, or those infected by wild-type phage and grown at $43^{\circ} \mathrm{C}$, is striking, for both the latter produce high yields of high molecular weight DNA. One may eliminate the possibility that the small DNA is a degradation product, because a chase with cold thymidine drives the label into the high molecular weight fraction. Further, Sugimoto et al. observe that incubation at $20^{\circ}-30^{\circ} \mathrm{C}$ of cells pulse labelled at $43^{\circ} \mathrm{C}$ leads to the rapid appearance of high molecular weight DNA, so that evidently the ligase is reactivated on cooling. This evidence appears to leave little room for doubt that DNA replication occurs by synthesis of short single-stranded lengths, followed by their assembly under the action of the ligase.

Spectacular use has been made of the T4 ligase by Khorana and his associates for the synthesis in vivo of predetermined DNA sequences. The object is nothing less than the synthesis of the gene for yeast alanine$t$ RNA. The latest report (Gupta et al., Proc. US Nat. Acad. Sci., 60, 1338; 1968) outlines the present state of progress-preparation of a deoxyribonucleotide duplex, corresponding to the last 30 nucleotides in the $t$ RNA sequence (nucleotides 21-50). The strategy consists of chemical synthesis of (say) two oligonucleotides with an overlapping segment of complementary sequence; these are then annealed together, to form a duplex, with a hanging, unpaired, "sticky", end. An oligomer complementary to this end is then added, pairs with it and is then linked to its adjoining segment by the ligase. The process may then be continued. Gupta et al. show in the first place that quite short duplexes will form at room temperature, though they are destabilized by the "sticky" ends. In marginal cases, where melting occurs near room temperature, the joining reaction is carried out at $5^{\circ} \mathrm{C}$, and the ligase will join something as short as a pentamer to another chain, in the presence of an appropriate complementary sequence. By the use of a ${ }^{32} \mathrm{P}$ label, and subsequent hydrolysis of the chain, they have shown that the join occurs in the anticipated place. No insuperable problems are foreseen in the synthesis of the remaining deoxyribo-oligonucleotides required to manufacture the complete alanine-tRNA gene.

\section{WORK SAFETY \\ Farming hazards}

\section{from a Correspondent}

THE mechanization of farming techniques and chemical control of weeds and pests has transformed agriculture in the United Kingdom since 1939. The 23rd conference of the British Occupational Health Society, held at Cambridge on September 17, was devoted to the health hazards which have resulted from these changes.

The hazards that accompany mechanization were discussed by C. J. Moss of the National Institute of Agricultural Engineering who pointed out that 30 40 per cent of accidental deaths on farms are caused by the overturning of tractors. Regulations which have been introduced recently should reduce this toll; similar legislation in Sweden has virtually eliminated deaths which arise from this cause. Better tractor design could also reduce noise, which sometimes exceeds the "hearing conservation" limit. It could also lessen the vibration from very "rough" diesel engines operating on uneven ground; this is probably responsible for the high incidence of stomach complaints and spinal deformity in tractor drivers. Risks which are not associated with tractors include the accumulation in glass-houses of carbon monoxide from petrol-driven cultivators, the noise of machines and of livestock in buildings.

Mr Alasdair Steele-Bodger, a veterinary surgeon, said that although agriculture is the most hazardous of British industries, few accidents are caused by animals. The increase in the number of animals per stockman creates problems, however, because stockmen no longer know individual animals and animals are less accustomed to humans. Mr E. S. Jamieson, an orthopaedic surgeon, pointed out that the pattern of injuries on farms is changing all the time, and many now resemble those seen in manufacturing industry. The small role of chemical hazards was underlined by Dr E. F. Edson, director of Fison's Chesterford Park Research Station. He maintained that the toxicity of pesticides has been much publicized, but they have accounted for only 14 out of about 2,500 accidental deaths on farms since 1946 and only 6 deaths have occurred since 1951. The fertilizers which are used at present are fairly harmless, but the highly concentrated ammonia and phosphoric acid used in North America could cause trouble if introduced here. Dr P. K. Fraser of the Public Health Laboratory at Ipswich described the diseases communicable from animals to man, but these are not an important health risk for farm workers.

The respiratory diseases of farm workers were discussed by Dr J. C. Gilson (MRC Pneumoconiosis Research Unit). Farmers suffer less from bronchitis than the general population, but are liable to mycoses which cause both infections and delayed hypersensitivity. They are also subject to the effects of toxic gases such as the oxides of nitrogen given off in silos. 